\title{
Inter-Relationships between Certain Rumen Ciliate Protozoa
}

\author{
BY J. MARGARET EADIE \\ Rowett Research Institute, Bucksburn, Aberdeen, Scotland
}

(Received 23 November 1961)

\begin{abstract}
SUMMARY
The establishment and components of the rumen ciliate population in a series of young animals has been followed using intra-ruminal inoculation with rumen material, and for comparison purposes the ciliate population in a number of adult ruminants has been examined. The fact that the ciliates Polyplastron multivesiculatum, Eudiplodinium maggii and Epidinium spp., though not host specific, did not form a stable mixed population was noted and experiments were carried out to examine the antogonism between certain of these organisms. The cause of the antagonism was not determined but cannibalism, food competition, or gross bacterial change did not seem to be responsible. It was found that the population of an adult animal could be changed by inoculation but the relationship between the ciliates appeared to be in some way affected by the host. It is concluded that inter-relationships of the type described may play an important role in determining the components of a particular rumen microfauna.
\end{abstract}

\section{INTRODUCTION}

The present paper will discuss in more detail the components of the ciliate populations in the series of young calves and lambs examined by Eadie (1962).

The presence of a certain degree of host specificity in rumen ciliates has been noted (see Dogiel, 1947). However, the ciliates used in the present investigation are those which are found naturally in both sheep and cattle.

In cannulated sheep (Eadie, 1962) the ciliate population tended to be a mixture of Entodinium spp., holotrich species and either type A large Ophryoscolecids, Polyplastron multivesiculatum (Dogiel \& Fedorowa) with various other species such as Diploplastron affine (Dogiel \& Fedorowa) and Ophryoscolex tricoronatus (Dogiel), or type B in which Eudiplodinium maggii (Fiorentini) and Epidinium spp., either together or alone, were the predominant large Ophryoscolecids. It became clear in the course of the work with artificial inoculations that the two types appeared to be unable to form a stable mixed population in sheep or cattle. Difficulties in establishing rumen bacterial species have been encountered by Hobson \& Mann (1961). This paper discusses the initial observations of antagonisms between rumen ciliates and describes further experiments carried out to investigate this problem.

\section{METHODS}

\section{Animals}

Tables 1 and 2 list most of the animals used in this work. Two kids were fed a ration similar to the lambs and were regularly inoculated with mixed rumen ciliates. The rations and management of the other young animals have already been 
recorded ('Tables 1, 2 and 3, Eadie, 1962). 43 and 74 were rumen-cannulated wethers.

Rumen contents were also examined from cattle and goats at this Institute, from red deer killed near Braemar, Aberdeenshire, and on the Isle of Rhum and fixed samples of rumen material from Zebu and Hereford cattle from Kenya were also used.

Stomach tube sampling and inoculation and the examination of samples

The routine procedure was that described by Eadie (1962). Where the inoculum was to contain a mixture of two possibly antagonistic populations the same separating procedure was used but the rumen liquors containing each type were kept apart until just prior to filling the McCartney bottle. The mixed inoculum used for lamb 232, for example, came from the same funnels and was therefore exactly comparable to the separate control inocula of types $\mathbf{A}$ and $\mathbf{B}$ given to lambs 230 and 231 , respectively.

When a change in population was thought to be imminent samples of at least $25 \mathrm{ml}$. were taken every 1-3 days. Before an organism was considered to be absent a survey had been made of all organisms in up to $2 \mathrm{ml}$. of whole rumen liquor in $0.1 \mathrm{ml}$. drops followed by examination of drops of fixed and concentrated material. Since the organisms were large and easily seen a negative result indicates that no organisms had been observed amongst ciliates from at least $5 \mathrm{ml}$. of rumen fluid as compared with thousands/ml. in an average population.

\section{Identification of the ciliates}

Without discussing in detail the controversial problem of classification it seems, nevertheless, essential that it is quite clear to which organisms this work refers. The problem of nomenclature, particularly for the organism Polyplastron multivesiculatum and even more so for the closely related Elytroplastron sp. has taken up much space in the literature, notably the papers of Becker (1933) and Wertheim (1935).

It should be emphasized that the author is completely satisfied that all the organisms referred to in this work by one particular specific name were of the same species. It was considerably more difficult in the case of Polyplastron multivesiculatum to determine what that species was. However, after careful examination of organisms from a sheep starved for $30 \mathrm{hr}$. and comparison with fixed specimens of $P$. multivesiculatum kindly sent from France by Dr C. Noirot-Timothee the presence of a small central dorsal skeletal plate was finally confirmed and the organism identified as $\boldsymbol{P}$. multivesiculatum. The three dorsal skeletal plates were not as sharply defined as Dogiel \& Fedorowa's diagram (1925) would suggest and as observed by Noirot-Timothee (1960) they were not joined by material of a skeletal plate nature so that the ' $M$ ' shape mentioned by Kofoid \& MacLennan (1932) is misleading. After re-examination of preserved specimens and consultation with Dr B. Sugden it has been concluded that organisms previously recorded as Metadinium medium, Awerinzew and Mutafowa (Sugden, 1953; Eadie, 1957) and those described by Eadie (1957) as Elytroplastron bubali (Dogiel) were all in fact $\boldsymbol{P}$. multivesiculatum.

In order to remain relatively consistent Kofoid \& MacLennan's classification 
rather than that of Dogiel has been used and where Dogiel's work is quoted the names used by Kofoid \& MacLennan have been substituted. The nomenclature used is therefore that of Lubinsky (1957) but differs from Noirot-Timothee (1960) in retaining the generic names Eremoplastron, Diploplastron, Metadinium and, particularly convenient for this work, retaining only Eudiplodinium maggii within the genus Eudiplodinium. This scheme has been chosen in order to describe the present work more easily rather than to express a theory of rumen ciliate systematics.

\section{RESUITS}

As previously noted (Eadie, 1962) both type A and B populations were found in different sheep although type $\mathbf{A}$ tended to be the most prevalent. In a number of mature cattle examined type $B$ was most frequently present but type $\mathbf{A}$ was not unknown. Ophryoscolex was not present in the sheep with type A which were used in this work, except in that used to provide the inocula for the two kids.

Tables 1 and 2 give a condensed summary of the following observations.

\section{Table 1. Observations on antagonism between rumen ciliate species in lambs and sheep}

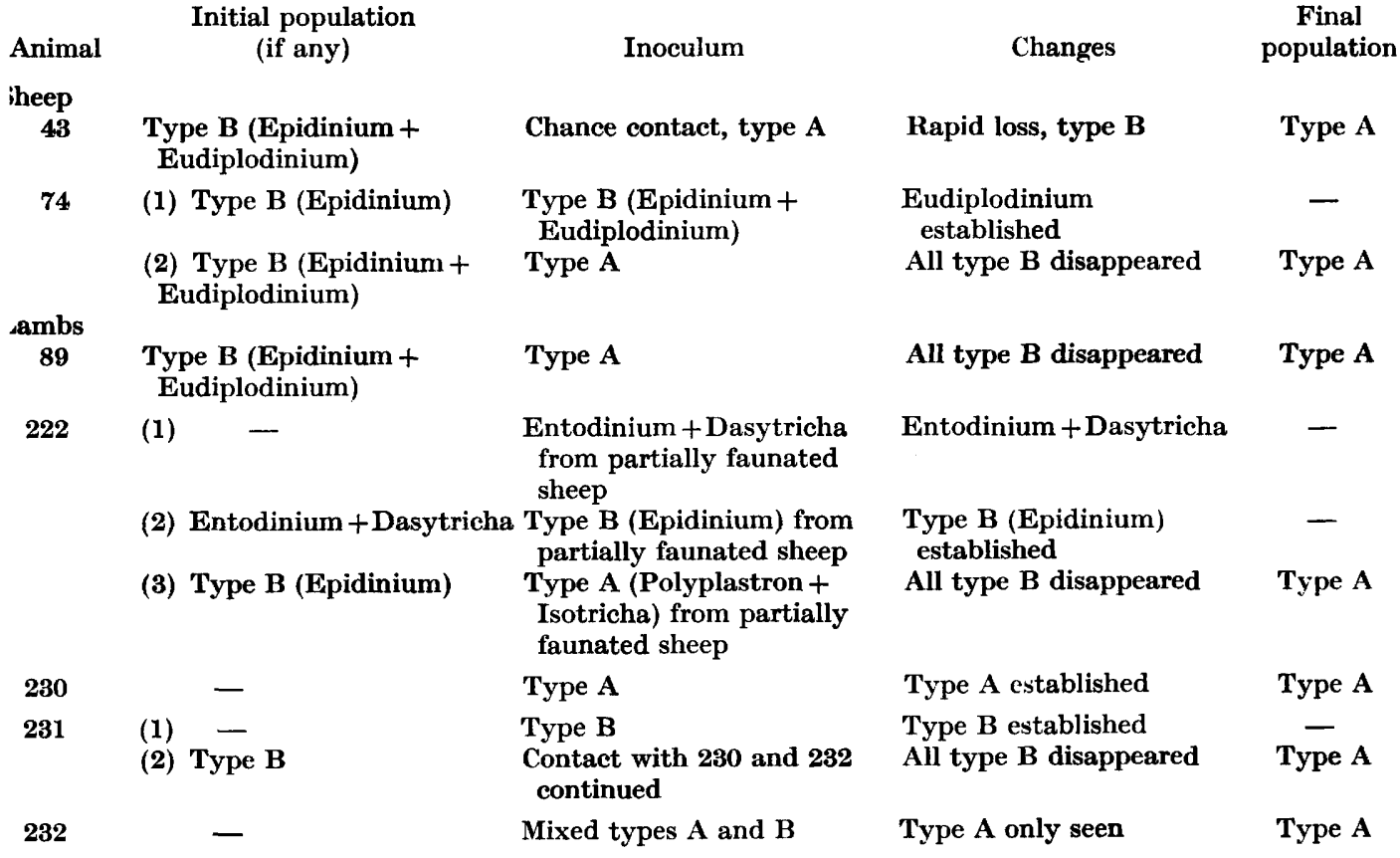

(a) Sheep and lambs. The first clear indication of antagonism was shown when the 18-month-old wether 43 which had had a steady population of type B organisms for at least 3 months, suddenly overnight 'lost' Epidinium and Eudiplodinium organisms and within 2 days contained large numbers of Polyplastron multivesiculatum, i.e. type A. The entodinia and holotrichs were unaffected. This animal was in a pen within contact with at least one sheep which contained type A organisms. The type A population has not changed again after 2 years. 
Next the 2-year-old wether $\mathbf{7 4}$ in which a type B population of Epidinium spp. but no Eudiplodinium, had been naturally established for at least 7 months, was inoculated with rumen liquor from a sheep containing a mixed type B population of Eudiplodinium maggii and Epidinium spp. Within 4 days Eudiplodinium was seen in sheep 74. One week later $400 \mathrm{ml}$. of rumen liquor containing type $A$ organisms was inoculated directly into the rumen cannula and the following day a few Polyplastron were seen. After 7 days a fair number of type B organisms were still present along with Polyplastron but by the 11th day only type A organisms

Table 2. Observations on antagonism between rumen ciliate species in calves

\begin{tabular}{|c|c|c|c|c|c|}
\hline Animal & & $\begin{array}{l}\text { Initial population } \\
\text { (if any) }\end{array}$ & Inoculum & Changes & $\begin{array}{c}\text { Final } \\
\text { population }\end{array}$ \\
\hline \multicolumn{6}{|l|}{ Calves } \\
\hline \multirow[t]{2}{*}{$\mathbf{3}$} & (1) & - & Type A alone & $\begin{array}{l}\text { Low pH-only Ento- } \\
\text { dinium spp. and holo- } \\
\text { trichs established }\end{array}$ & 一 \\
\hline & (2) & Entodinium + holotrichs & Mixture of types A and B & $\begin{array}{l}\text { Type B seen first then } \\
\text { mixture and finally A }\end{array}$ & Type A \\
\hline 4 & $\begin{array}{l}\text { (1) } \\
(2)\end{array}$ & Type A & $\begin{array}{l}\text { Type } A \text { alone } \\
\text { Mixture of types } A \text { and } B\end{array}$ & $\begin{array}{l}\text { Type A established } \\
\text { Type A only seen }\end{array}$ & Type A \\
\hline \multirow[t]{2}{*}{$\mathbf{3 5}$} & (1) & - & $\begin{array}{l}\text { Mixture of types } A \text { and } B \\
\text { (Epidinium) }\end{array}$ & Type B (Epidinium) & - \\
\hline & (2) & Type B (Epidinium) & $\begin{array}{l}\text { Mixture of types A and B } \\
\text { (Epidinium + Eudiplo- } \\
\text { dinium) alternated with } \\
\text { type } \mathbf{A} \text { alone }\end{array}$ & $\begin{array}{l}\text { Type B (Eudiplodinium + } \\
\text { Epidinium) }\end{array}$ & Type B \\
\hline ' $\mathbf{N}$ ' & $\begin{array}{l}\text { (1) } \\
\text { (2) }\end{array}$ & Type A & $\begin{array}{l}\text { Inoculated type A } \\
\text { Contact with animals } \\
\text { with type } B \text { and cross- } \\
\text { inoculation from ' } O \text { ' }\end{array}$ & $\begin{array}{l}\text { Type A } \\
\text { First type B but finally } \\
\text { A only }\end{array}$ & Type A \\
\hline ' $\mathrm{O}$ ' & $\begin{array}{l}\text { (1) } \\
\text { (2) }\end{array}$ & $\begin{array}{l}\text { Small Entodinium spp. } \\
\text { Mixed type B (i.e. } \\
\text { including Ostraco- } \\
\text { dinium spp. \& Eremo- } \\
\text { plastron spp. }\end{array}$ & $\begin{array}{l}\text { Contact mature animals } \\
\text { Cross-inoculation from ' } N \text { ' }\end{array}$ & $\begin{array}{l}\text { Mixed type B } \\
\text { Type B disappeared }\end{array}$ & Type A \\
\hline \multirow[t]{3}{*}{ ' $F$ ' } & & $\begin{array}{l}\text { Short time type B } \\
\text { (Eudiplodinium) }\end{array}$ & Type A & Type A established & - \\
\hline & (2) & Type A & $\begin{array}{l}\text { Series inoculations of } \\
\text { alternate types } A \text { and } B\end{array}$ & $\begin{array}{l}\text { Type B (Eudiplodinium) } \\
\text { stayed } 5 \text { weeks }\end{array}$ & - \\
\hline & (3) & Type B (Eudiplodinium) & Left without inocula & $\begin{array}{l}\text { Wavered considerably and } \\
\text { mixed for periods. } \\
\text { Finally type B } \\
\text { (Eudiplodinium) }\end{array}$ & Type B \\
\hline \multirow[t]{2}{*}{ 'G' } & & - & Inoculated type B & $\begin{array}{l}\text { Type B (Eudiplodinium) } \\
\text { established }\end{array}$ & - \\
\hline & & pe B (Eudiplodinium) & $\begin{array}{c}\text { Inoculated alternately } \\
\text { with types } A \text { and } B\end{array}$ & $\begin{array}{l}\text { Type B (Eudiplodinium) } \\
\text { remained }\end{array}$ & Type B \\
\hline
\end{tabular}

remained, although not in large numbers. Attempts were made to re-establish type B organisms by inoculation of $500 \mathrm{ml}$. volumes of whole rumen liquor from the sheep which had earlier been used to establish Eudiplodinium (see above), but the change to type $A$ seemed to be irreversible and remains so. It is of interest that no type $\mathbf{B}$ organisms were ever observed even transitorily, after the inoculations, in contrast to certain observations in experiments with calves (see later). 
A further experiment was carried out with lamb 89 in which a thriving type B population had been established by direct contact with the ewe. At 4 months of age it was inoculated with whole rumen liquor of type $\mathbf{A}$ and within one week all type $\mathbf{B}$ organisms had disappeared and only type A remained. Again the change proved irreversible, which showed with certainty that this was a feature of the ciliates and bore no relation to the original inoculum given to the lamb. The early history of sheep 43 and 74 was not known so that the change might have been a reversion to an earlier established population. However the fact that type $B$ had been the only population in lamb 89 since birth ruled out this possibility.

Having proved that an established type $B$ population in sheep could be changed by inoculation with type $\mathbf{A}$, even if the inoculum was quite small as must have been the case in the natural inoculations of sheep 43, it became of interest to determine if a mixture of populations could be achieved when both types were given an equal opportunity to become established in a young lamb. For this the mixed inoculum prepared as described under 'Methods' was used for lamb 232 from 18 days old. Control lambs 230 and 231 were inoculated with types $\mathbf{A}$ and B populations, respectively, and all three lambs were kept together in one pen. It was of interest that holotrichs were absent from the type $\mathbf{B}$ inoculum used. When inoculation was terminated at 46 days old, lamb 230 had a type $A$ population and lamb 231 had type $B$ as inoculated, i.e. without holotrichs. This proved that both populations were perfectly viable. However, lamb 232 had only a type A population and no organisms of type $\mathbf{B}$ were ever seen. The lambs were kept together and the populations remained unchanged up to 115 days old. On that day holotrichs were first seen in lamb 231 which proved that there had been transference from 230 or 232 . One week later the previously thriving population of type B organisms had completely disappeared from lamb 231 and type A alone was present. Once again there was no reversion.

The final experiment with sheep was carried out on lamb 222 after isolation (see Eadie, 1962). This was partly to confirm that isolation did not alter the relationships between ciliates and that the antagonism was found irrespective of the number of ciliate species present. When Entodinium spp., Dasytricha sp. and Epidinium spp. had been established by inoculations from a partially defaunated sheep containing these species alone (Eadie, 1962), a population of type A from another isolated sheep containing only Polyplastron multivesiculatum, Entodinium spp. and Isotricha spp. was inoculated into lamb 222. Both Epidinium (type B) and Polyplastron (type A) were seen for 5 days but on the 6 th day the only large Ophryoscolecid which remained was Polyplastron (type A). In this sheep the holotrich organisms were rather slow to increase in number so that, in fact, at the time of change other than Polyplastron and Epidinium, only entodinia species were present in any significant numbers. This experiment therefore confirmed a direct relationship between the Polyplastron of type A population and Epidinium of type $B$.

(b) Calves. From Table 2 it can be seen that experiments similar to those in the lambs were carried out with calves.

In the young calves, 3,4 and 35 , a mixed inoculum was used. In calf 4 the type $A$ population alone persisted though on one day a mixture was seen. In calf 3 type $B$ first became established but was later replaced by type A. In calf 35, however, none of the type A Ophryoscolecids were ever seen but type B became established 
from 56 days of age and even where large inocula from sheep containing type A were given, type $\mathrm{B}$ remained in this calf. These results show a contrast between lambs and calves in that type $\mathbf{A}$ had always been completely dominant in sheep.

In the three experiments described above the inocula were all taken from sheep. Observations on the antagonism were also made on calves ' $N$ ' and ' $O$ ' where ' $N$ ' had initially been inoculated with type A from sheep but relatively few ciliates had developed. Calf ' $\mathrm{O}$ ' developed a mixed type $\mathrm{B}$ population by direct contact with other calves when both calves were turned out to grass at 164 days and inoculations were stopped. This population in ' O' included Ostracodinium spp. and Eremoplastron spp. as subsidiary type B organisms. Gradually, while still in contact with other calves, the type $A$ organisms in calf ' $N$ ' disappeared and type $B$ organisms developed and were quite numerous 7 weeks after calf ' $O$ "'s population had been established. One week later, however, the population in calf ' $N$ ' had reverted to type A.

At this stage the calves ' $N$ ' with type A organisms and ' $O$ ' with type $B$ organisms were cross-inoculated several times with up to $150 \mathrm{ml}$. of whole rumen liquor. Calf ' $N$ ' showed only type A organisms throughout. Calf ' $O$ ' began to have a few Polyplastron (A) and 3 weeks after the first cross-inoculation only type A remained and all type $\mathrm{B}$, including the subsidiary species, had disappeared. Cross-inoculation was stopped but type $A$ remained stable in both calves for the next 2 months at which stage sampling was stopped.

Finally, twin calves ' $F$ ' and ' $G$ ' were used in antagonism investigations. Calf ' $F$ ' following an initial period with type $B$, developed type $A$ after inocula of this type had been given regularly. Calf ' $G$ ', after isolation for 9 months, was inoculated with type $\mathbf{B}$ which became rapidly established. A series of alternate inoculations with types $\mathbf{A}$ and $\mathbf{B}$ in turn, were then made to both calves and an interval of up to 4 weeks was left between inoculations. Despite the large volumes of inocula of type A, type $B$ persisted in calf ' $G$ ' and no organisms of type $A$ were ever seen. In calf ' $F$ ', on the other hand, the population wavered considerably and at the time the last inoculation of type A was given Eudiplodinium (type B) had persisted for 5 weeks though Epidinium (B) had failed to establish even after large numbers were given from the partially defaunated sheep containing that organism.

Three weeks after the final inoculation of calf ' $F$ ' with type A, type B was still the only one seen. However, during the next 4 months when no inocula were being given and the animals were still being kept apart, the population again wavered. Polyplastron (type A) developed along with type B Eudiplodinium organisms for a period of 2 weeks and type $A$ was then present alone for a further 2 weeks. There followed another short time with the mixture and finally type B became predominant and type A disappeared. This was the only occasion on which Polyplastron (type A), having once been observed in either a calf or a lamb, did not become predominant and it is particularly remarkable in that for several weeks it had virtually been the only large Ophryoscolecid. 


\section{General observations on the antagonism}

(a) There was no change in the bacterial Gram smear picture to coincide with alterations in ciliate population.

(b) The frequent presence within the protozoa of parasites of the genus Sphaerita described by Lubinsky (1955) appeared to bear no relation to the antagonism.

(c) Cannibalism was not observed.

(d) The rations fed differed (Eadie, 1962) so that a particular food material was not significant.

(e) Since on occasion a large number of type B organisms were replaced by relatively few type $\mathbf{A}$ organisms direct competition for food seemed unlikely.

( $f$ ) Neither entodinia nor the holotrich ciliates were involved in the changes.

(g) Whether Epidinium and Eudiplodinium were together or alone in a type B population seemed immaterial and from calf ' $O$ ' it appeared that other species could be involved in a type $B$ population.

(h) Diploplastron affine tended to be associated with type A only. The position of Ophryoscolex is discussed later.

(i) When the population in calf ' $F$ ' included both types some unusually large Eudiplodinium organisms were observed. Some organisms were dividing and were, therefore, larger but the width was up to $40 \mu$ greater than the largest from a comparable 'normal' population. The sizes did not correspond to the large and small organisms described by Fiorentini (1889) as E. maggii and Diplodinium bursa.

\section{Observations of ciliate populations from other hosts and at other times}

Eudiplodinium maggii and Epidinium spp. can exist with some other large Ophryoscolecid species since they were observed along with organisms of the genus Metadinium in deer and in Hereford and Zebu cattle from Kenya and in the latter the largest recorded Ophryoscolecid Eremoplastron giganteum (Dogiel) was also present. This species had previously only been recorded from wild ruminants in Africa (Dogiel, 1925).

Polyplastron multivesiculatum has been observed by the present author in association with two other fairly large Ophryoscolecids; with Enoploplastron triloricatum (Dogiel) in sheep from North Ronaldsay and with Ophryoscolex tricoronatus in several sheep at this Institute. Ophryoscolex could be established with Polyplastron in mature sheep but as mentioned by Eadie (1962) it did not readily become established in either lambs or calves. It developed in one kid at 4 months of age, though in other respects the kids were similar to lambs. With no known stimulus Ophryoscolex died out in the population of one old sheep in spring, 1958 and in two others in late $\mathbf{1 9 5 9}$ and it seemed therefore to be less firmly established than Polyplastron.

\section{DISCUSSION}

Kofoid \& MacLennan (1933) remark upon the tendency for certain species of rumen ciliate to appear in one host 'in preference' to another. This is also clear from Dogiel's observations (Dogiel, 1947). Becker (1932) in referring to this apparent mild form of specificity poses the question of whether this is due to 'unequal distribution due to specifically adapted infusoria or to individual physiological 
properties of the various host species'. The observations on antagonism between ciliate species in the present work may partly solve this question of variation in ciliate populations between animals and between host species. Nevertheless, the presence of Eremoplastron giganteum (Dogiel) in Zebu cattle from Kenya and not in the neighbouring Hereford animals, might indicate that certain of Dogiel's ideas of host specificity are valid.

Unfortunately in the papers which record the presence of Polyplastron multivesiculatum there is no record of the other species found in the same host individual, though Dogiel \& Fedorowa-Vinogradova (1925) state that Polyplastron is frequent in cattle and sheep. Wertheim (1935) lists cattle, sheep and goats as the recorded hosts. Dr Noirot-Timothee (private communication) has noted that, though in the majority of samples from sheep and cattle which she has examined types $A$ and $B$ were separate, in only a small number of cases she found Polyplastron in the same population with Eudiplodinium maggii and even less frequently with Epidinium spp. Unfortunately there were isolated observations and it seems possible that a series of samples from the same animals might have shown that the populations were in the process of changing (see calf ' $F$ '). The cross-inoculation work of Dogiel \& Fedorowa-Vinogradova (1930) can more easily be compared with the present findings. Early in their paper the Russian workers listed 19 species which they had recorded from goats and this list included Polyplastron, Epidinium and Eudiplodinium. In their experiments goats partially defaunated by starvation methods were inoculated with rumen contents pooled from several bulls killed at the slaughter house. Although Dogiel \& Fedorowa's interest was in the species which established and not in the relationship between the ciliates themselves, several similarities to the results of the present work can be seen. Eudiplodinium maggii, Epidinium and Polyplastron never became established together. In one experiment Polyplastron became established in a goat already containing Diploplastron affine and Diplodinium caudatum and on this occasion the authors noted the temporary presence of small numbers of $\boldsymbol{E}$. maggii, Eremoplastron spp., Ostracodinium spp. and Metadinium medium for 3 days after inoculation after which they 'probably died'. When this animal was re-inoculated Polyplastron disappeared and $M$. medium and Eremoplastron became established. Dogiel \& Fedorowa checked that the established species were not necessarily those most numerous in the inocula but they explained the observations on the basis of different susceptibility to the conditions in the goat. It seems clear that they were confronted with the same type of antagonism between ciliates as is described in the present work. Our observations on kids and goats have indicated a strong similarity to sheep.

The specific factors involved in the antagonism are not clear but the fact that it exists is beyond doubt. Although the ciliates concerned display no host specificity a definite host effect has been observed in that type $\mathbf{A}$ though dominant in sheep was less so in cattle and in fact, type $B$ displayed dominance in calves 35 , ' $F$ ' and ' $G$ ' under the same conditions. This type of variation might lead to host population differences of the kind observed by Dogiel. The fact that considerable time may elapse before contact effects transfer between animals, as in the case of lamb 231, is rather a surprising observation but it is nevertheless clear that natural contact may be completely effective in altering a population from a non-dominant type. It seems probable that other species of ciliate may show mutual antagonisms, as for 
example that between Metadinium medium and Polyplastron indicated by Dogiel \& Fedorowa's work (1925) and it is hoped to examine this further.

At present it is not possible to correlate antagonism with food competition, cannibalism or gross bacterial population changes nor even with the species regarded as evolutionarily the most complex since Dogiel (1947) and Lubinsky (1957) both place Ophryoscolex at least as high or at a higher level than Polyplastron. Similarly, large size does not in itself seem to be significant since Eremoplastron giganteum was associated with Eudiplodinium and Epidinium. The large size of certain Eudiplodinium organisms in the mixed population of calf ' $F$ ' has not been explained. The fact that apparently closely related species may not have the same antagonistic properties is illustrated by the records of Elytroplastron bubali, since out of the ten buffaloes and goats from which Elytroplastron was obtained in at least seven cases organisms of type A were also found (Dogiel, 1928; Das Gupta, 1935).

The presence of antagonism between rumen ciliates indicates that the initial large ciliate population transferred to the young ruminant from the dam is not only subject to change through alteration in rumen conditions caused by a change in ration (Eadie, 1962) but also through the 'take-over' by an antagonistic species and in order fairly to assess the establishment of a particular ciliate species in a ruminant host it is necessary to consider that species in relation to the rumen ciliate population as a whole. Thus the factors which govern the development of a rumen ciliate fauna are not as straightforward as was first believed.

I am most grateful to Dr B. Sugden and Dr C. Noirot-Timothee for their help in the identification of Polyplastron multivesiculatum and to Mr G. Philip for making available the samples from Kenya. I should also like to thank Dr P. N. Hobson for his advice and encouragement and $\mathrm{Mr}$ W. Shand for continual technical assistance.

\section{REFERENCES}

Becker, E. R. (1932). The present status of problems relating to the ciliates of ruminants and Equidae. Quart. Rev. Biol. 7, 282.

BECKER, E. R. (1933). Concerning Elytroplastron hegneri, Becker \& Talbott, 1927. Trans. Amer. micr. Soc. 52, 217.

Das Gupta, M. (1935). Preliminary observations on the protozoan fauna of the rumen of the India goat Capra hircus Linn. Arch. Protistenk. 85, 153.

Dogies, V. A. (1925). Nouveaux infusoires des famille des Ophryoscolecides parasites d'antilopes africaines. Ann. Parasit. hum. comp. 3, 116.

Dogies, V. A. (1928). La faune d'infusoires habitant l'estomac du buffle et du dromadaire. Ann. Parasit. hum. comp. 6, 328.

Dogrel, V. A. (1947). The phylogeny of the stomach-infusorians of ruminants in the light of palaeontological and parasitological data. Quart. J. micr. Sci. 88, 337.

Dogiel, V. A. \& Fedorowa-Vinogradova, T. (1925). Ueber den Bau und die Funktion des inneren Skeletts der Ophryoscoleciden. Zool. Anz. 62, 97.

Dogiel, V. A. \& Fedorowa-Vinogradova, T. (1930). Experimental studies on the biology of infusoria from the stomach of ruminants (Russian with English summary). Bull. Inst. Agric. Microbiol. Leningrad, 4, 157. See also Wiss. Archiv. für Landweirtschaft (1930), 3, 172.

EADIE, J. M. (1957). The mid-winter rumen microfauna of the seaweed-eating sheep of North Ronaldsay. Proc. roy. Soc. Edin. Section B, 66, 276.

EADIE, J. M. (1962). The development of rumen microbial populations in lambs and calves under various conditions of management. J. gen. Microbiol. 29, 563. 
Frorentini, A. (1889). Intorno ai Protisti-dello stomaco dei Bovini, pp. 1-27. Pavia.

Hobson, P. N. \& MaNN, S. O. (1961). Experiments relating to the survival of bacteria introduced into the sheep rumen. J. gen. Microbiol. 24, i.

Kofoid, C. A. \& Maclennan, R. F. (1932). Ciliates from Bos Indicus Linn. II. A revision of Diplodinium Schuberg. Univ. Calif. Publ. Zool. 37, 53.

Kofoid, C. A. \& MacLennan, R. F. (1933). Ciliates from Bos Indicus Linn. III. Epidinium Crawley, Epiplastron gen.nov., and Ophryoscolex Stein. Univ. Calif. Publ. Zool. 39, 1.

Lubinsky, G. (1955). On some parasites of parasitic protozoa 1. Sphaerita hoari sp.n.a chytrid parasitizing Eremoplastron bovis. Canad. J. Microbiol. 1, 440.

Lubinsky, G. (1957). Studies on the evolution of the Ophryoscolecidae (Ciliata: Oligotricha) III. Phylogeny of the Ophryoscolecidae based on their comparative morphology. Canad. J. Zool. 35, 141.

Norrot-Trmothee, C. (1960). Etude d'une famille de cilies: les 'Ophryoscolecidae'. Structures et ultrastructures. Ann. Sci. nat. b. 12, Serie, 527.

SuGDEN, B. (1953). The cultivation and metabolism of oligotrich protozoa from the sheep's rumen. J. gen. Microbiol. 9, 44.

Wertheim, P. (1935). The revision, systematic position and origin of Diplodinium (Polyplastron) multivesiculatum and Diplodinium (Polyplastron) bubali. Quart. J. micr. Sci. 78, 31. 